\title{
Conflict Potential of Interethnic Relations and Migration Processes in the Russian Regions: Ethnoinstitutional Methodology of Analyses
}

\author{
Elena Yurievna Bazhenova ${ }^{1}$, Anton Vladimirovich Serikov ${ }^{1}$, Irina Borisovna Serikova ${ }^{1}$ \& Darya Nikolaevna \\ Stukalova ${ }^{1}$ \\ ${ }^{1}$ Southern Federal University, Russia \\ Correspondence: Darya Nikolaevna Stukalova, 160, Pushkinskaya st., 344007, Rostov-on-Don, Russia.
}

Received: November 1, 2014

Accepted: December 23, 2014 Online Published: March 16, 2015

doi:10.5539/ass.v11n $7 \mathrm{p} 252$

URL: http://dx.doi.org/10.5539/ass.v11n7p252

\begin{abstract}
The article defines ethnoinstitutional factors in migration and interethnic relations. Ethnic institutions (ethnoinstituions) are regarded as stable complexes of individual and collective behavioral norms and motivations, mediated by ethnic culture and identity. The article shows that the conflict potential of migration is primarily associated with incompatibility of host and arriving population ethnoinstitutions. It is necessary to develop transmitting institutions to reduce the conflict potential of interethnic relations. Such institutions should be able to "translate" ethnoinstitutional requirements of the host community in the form which will motivate migrants to accept the local rules and behavior patterns.
\end{abstract}

Keywords: conflict, ethnic institutions, ethnicity, migration, diaspora, regions, the South of Russia

\section{Introduction}

Nowadays Russia is a part of global migration system which became caught up in both regional and global migratory flows (Flynn, 2004). Migration has a direct impact on a conflict potential in one or another region, and should be considered as an important factor of ethnic conflicts mobilization (Russian nationalism..., 2009). Intensive migration processes continues in the regions of the South of Russia (Kurabtsev, 2010). In contrast to the large Russian cities, where a significant proportion of migrants are foreigners, in this case we are talking mainly about domestic (or internal) migrants from the North Caucasus. Despite the fact that internal migrants speak Russian and have Russian citizenship even a small change in the ethnic composition of a particular rural society often leads to an increase in interethnic tension (Rozanova, 2010). These processes also occur in urban environment, but they occur on the basis of a broader categorization - not different ethnicity, but different culture (for example, just "Caucasians" instead of some other ethnonyms) with generation numerous stereotypes in mass consciousness and media (Morgunova, 2010).

Increasing of conflict potential is accompanied by a discursive designing of the accusations against migrants by reason of their indisposition for respecting local customs and traditions, and countercharges by migrants towards local population by virtue of its stereotypes and xenophobia captivity, while mass and social media broadcast negative images of migrants (Losifides, 2011). In this case, the real conflicts are merely partly random, in a great measure they reflect a regular tendency associated with discomplementarity of ethnoinstitutions of host community and migrants (Zhou, 2013). The official discourse, in fact, is deprived of concepts that describe these antagonisms, as a consequence interethnic collisions are formulated by official authorities, mostly, as "household".

\section{Methods}

In sociological literature antimigrant attitudes of host population are explained with different theoretical constructions (Alexseev, 2006). In our opinion the conflict potential of migration flows can be investigated on the basis of exposure of complementarity and antagonisms between the structure of regional or local community ethnoinstitutions and the nature of arriving population ethnoinstitutions. In this case, basic parameters of analysis are, on the one hand, consolidation of host community ethnoinstitutions and its ability to integrate arriving population by various methods and, on the other hand, the willingness and ability of arriving population to integrate and adapt. The last two parameters depend on a strength of arriving population ethnoinstitutions, an 
ability of ethnic groups of migrants to consolidate or became an enclave and weight of their own ethnoinstitutions.

Before concretizing given theses, turn to several theoretical definitions. Trying to develop within the framework of neo-institutional approach the original concept, which would describe and explain the processes of ethnogenesis by means of institutional methodology, as well as processes of ethnic differentiation and integration (ethnoinstitutionalism), M. Barbashin suggested efficient concept of the "ethnoinstitute" (Barbashin, 2012). Ethnoinstitute is a set of norms (impulses and rules) and motivations, reproduced in the framework of an ethnic group and determining behavior patterns within an individual strategy of utility maximization of social action and collective strategies for resolving social dilemmas.

Noting the generally high heuristic potential of such definition, we take the view that does not include the methodological premise of ethnoinstitutionalism in this definition. That is, we suppose that ethnoinstitutes are the important part of ethnosphere indeed, but they can be simply defined as stable sets of rules that reproduce certain models of individual or collective ethnosocial behavior mediated by ethnic identity and culture. By this definition, regard as of paramount importance is not rational premise that one or the other ethnoinstitute is primarily a function of the solution to a social dilemma, but the interpretation of ethnoinstitute as a method of social action mediated by tradition and culture, as well as group identity (Gorenburg, 2003).

When we talk about the problems of migration in Russia, we must also bear in mind that migration flows have not only ethnic, linguistic, and even civilizational dimension. The most important aspect is bringing norms, values and institutions of traditional society into a more or less modernized society. That is why, interviewed experts say, even on its own ethnicity (otherness) becomes a conflictual factor. Referring to the traditional society, ethnicity mobilizes institutions competition at all levels - economic, behavioural, axiological and symbolical (Karanov, 2013).

Peculiarity of ethnicity as a social phenomenon is that, all the above mentioned factors of conflictogenity, can be combined and move into one another. For example, ethnic minorities may consider one or another feature of the dominant culture as cultural aggression, and, vice versa, one or another behavior that is interpreted by a representative of an ethnic minority as a predominantly cultural expression (e.g., lezginka (Note 1)), can be seen by the host population as an act of cultural aggression, as an attempt to indicate their social space, position, domination by cultural markers (lezginka in a public place or in a public place and nighttime).

\section{Results}

\subsection{The Level of Social Tension}

Below we consider some empirical data obtained in the course of complex sociological study conducted in the Rostov region, Russia, in 2013 (Note 2). Region average about two-thirds of the population experience animosity with varying degree of frequency to people of another ethnicity (Figure 1). What causes such a level of intensity? First of all, it is a conflict potential of socio-cultural and socio-economic interaction most likely generated by waves of migration in the region. Both of these aspects need to be systematically and consistently regulated. Another factor is the general trend of strengthening the role of ethnic identity among the Russian population. In the recent past, those Russian people who do not attach particular importance to national identity and identify themselves primarily with the state, highlight ethnoidentity today (Barkov et al., 2013).

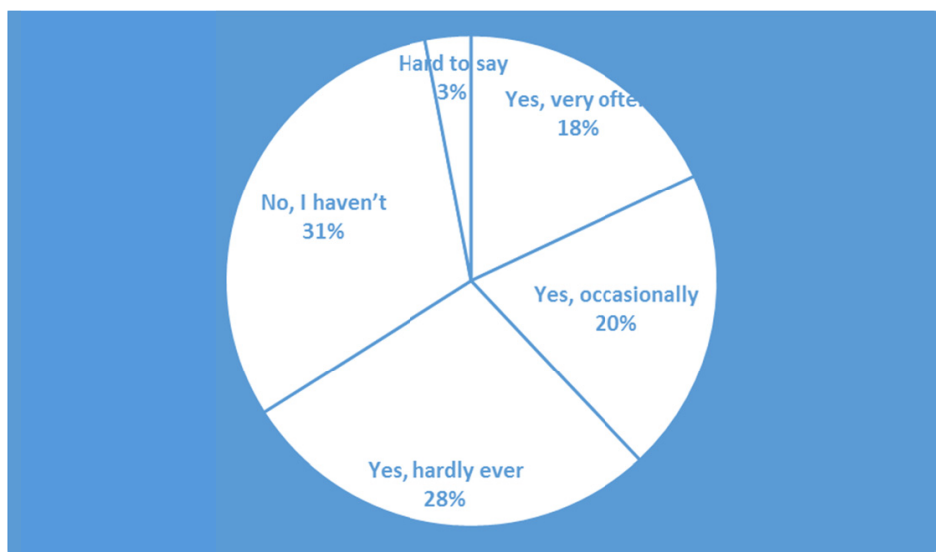

Figure 1. Distribution of answers to the question "Have you ever had a dislike to people of another ethnicity?" 
The proximity of the Northern Caucasus affects social tension and interethnic relations in the Rostov region, first of all, by way of actualization of the social problems associated with increasing migration, lack of adaptation of migrants to the conditions and requirements of the host community. Known events in Rostov-on-Don after the murder of one student from a Rostov university another student from the North Caucasus are the prime example of a spontaneous protest activity, manifestation of latent social tension, waiting for a convenient occasion and events for its transformation in protest (Police arrested.., 2010).

Table 1 shows the cross-tabular comparative factors illustrating the importance of different social grounds to respondents, which form and secure dislike on a national basis.

Table 1. Distribution of answers to the question "How connected, do you think, dislike on ethnic grounds with the following circumstances?"

\begin{tabular}{cccc}
\hline Circumstances & \multicolumn{2}{c}{ The degree of connection (\% of respondents) } \\
\hline With a difference in people's behavior, lifestyle & $\begin{array}{c}\text { Strongly } \\
\text { connected }\end{array}$ & $\begin{array}{c}\text { Connected, but } \\
\text { weakly }\end{array}$ & $\begin{array}{c}\text { It is not } \\
\text { connected }\end{array}$ \\
With the competition in the labor market & 58 & 25 & 17 \\
With the fact that people of other nationalities do not & 18 & 39 & 43 \\
comply with the customs and traditions of the region & 72 & 19 & 7 \\
\hline
\end{tabular}

As respondents' answers demonstrate, the hostility is formed mainly due to the fact that migrants do not respect and do not strive to respect local customs and traditions (72\%). The differences in lifestyle, behavior patterns, as conditions for the formation of hostility (58\%), are very significant. And only $18 \%$ of respondents note that hostility is formed largely due to competition in the labor market.

The question may arise, how do the first position ("failure to follow local customs") so much differ from the second ("differences in behavior")? It is clear that the first item describes such situations, when newcomers ignore, first of all, rules of social life with a local population. Consequently, they seem to accomplish expansion of their behavioral models in a public space. In other words, if they showed their habits and features in a private social space, the reasons for a formation of hostility would not arise (Tsyganov, 2006). The second position deal with a rejection of alien cultural patterns, lifestyle, values. In such a case, obviously we should understand that a perception of an alien way of life, its differences and tolerance to these differences is a consequence of precisely the availability of cultural stereotypes, authoritarianism of their own cultural identity.

Experts interviewed in the research were identified such phenomenon as the transfer of a conflict of interest to a conflict on ethnic grounds: "The exceptions are people whose daily practices intersect with activities of migrants or diasporas (trade, services) and, thus, their interests intersect with those of other nationalities. In this case, the transfer of a conflict of interest to a conflict on ethnic grounds may take place, especially if active using of ethno- resource occurs". Indeed, something similar we have seen in the comments made by some respondents that gave an assessment of the problems of interethnic relations in trade.

\subsection{The Role of Diasporas in Interethnic Relations}

In our opinion, diaspora is one of the most important ethnoinstitute, and it may be at different stages of development as an institution in each ethnic group living in a particular region - be unformed, work on an informal level as a social network and a set of patterns of collective mobilization in case of a conflict, or to function as a formal organization (system of organizations) (Toschenko \& Chaptykova, 1996). In this context, it is interesting to classify answers to the question of diaspora's responsibility for their nationality representatives in the region. Most of the population (56\%), indeed, holds such a responsibility on the diaspora (Table 2). Another $42 \%$ holds, at least functions of education and advocacy, outreach (to follow the rules and customs of the local community).

In our opinion, this ratio can be regarded as a kind of social inquiry, which may touch upon the problem of public recognition of the institute of diasporas and autonomies: people are ready to acknowledge their role and authority, but they demand responsible and effective actions of control the behavior of tribesmen in response. Thus, after that the diaspora is recognized by public opinion as an ethnoinstitute. It is a transitive ethnoinstitute, 
which is able to "translate" social demands of the host community to "institutional language" of different ethnic community. Further confirmation of this statement is the data in the table $4:$ more than $60 \%$ of respondents do not rule out the possibility to appeal to representatives of the diaspora for conflict resolution. And only $25 \%$ of respondents insist on the universalist approach - conflict must be solved not through the institutions of authority or group coercion, but by means of law-enforcement agencies.

Table 2. Distribution of answers to the question "Do you think should an ethnical diasporas to be responsible for representatives of their own ethnicity in the region?" (in \% of respondents)

\begin{tabular}{lc}
\hline \multicolumn{1}{c}{ Possible answers } & Frequency, \% of respondents \\
\hline 1) Yes, they should contribute to their legal behavior. & 56 \\
2) Yes, they should to conduct explanatory work. & 42 \\
3) No, it is not their competence. & 17 \\
4) Hard to say. & 7 \\
\hline
\end{tabular}

Table 3. Distribution of answers to the question "In case of conflict or misunderstanding with a representative of a different ethnicity, would you like to appeal to the his (or her) diaspora (the elders, leaders, etc.) to resolve the dispute?" (in \% of respondents)

\begin{tabular}{lc}
\hline \multicolumn{1}{c}{ Possible answers } & $\begin{array}{c}\text { Frequency, \% of } \\
\text { respondents }\end{array}$ \\
\hline 1) Yes, I would appeal to clarify my own position and demand a fair trial. & 32 \\
2) I might turn to, but I'm not sure. & 29 \\
3) No. I wouldn't appeal, it is useless. Such cases are within the competence of law \\
enforcement agencies. \\
4) No, I wouldn't appeal because I do not need it. I have my own opportunities to \\
resolve the conflict. \\
5) Hard to say.
\end{tabular}

The representative factor that the potential popularity of diasporas as institutions for settlement of disputes and conflicts is higher than the popularity of responsible state bodies (Ministry of Internal Affairs, Prosecutor's Office, etc.) should be pointed out. Low level of social trust in law enforcement makes people look for more effective institutional ways of resolving ethno-institutional contradictions (Gudkov, 2012). It seems like an objective fact, which should be reflected in the state national policy.

The transfer principle of the social responsibility of an ethno-national community for its members is actually quite common in modern practice. Obviously, it is not a collective responsibility for the offense, etc. The idea is that building an effective relationship with diasporas is an important tool of an interethnic relations management (Citizenship \& Immigration Canada, 2014). The main objective is to establish rapidly social connection between a migrant with a host community by means of a diaspora.

Table 4. Distribution of answers to the question "What is your attitude towards migrants, displaced people in your city, area?" (in \% of respondents)

\begin{tabular}{lc}
\hline \multicolumn{1}{c}{ Possible answers } & Frequency, \% of respondents \\
\hline 1) I think that migration processes should be stopped. & 8 \\
2) I think that migration processes should be significantly limited. & 54 \\
3) I don't care. & 15 \\
4) I sympathize with migrants and I think that they need support. & 15 \\
5) Hard to say. & 8 \\
\hline
\end{tabular}

At the same time the general level of migrantophobia (hostility towards migrants) is about 26\% (Table 6). Other respondents either sympathize with migrants $(36 \%)$, or treat them with indifference $(29 \%)$. Comparison of the data in the Tables 4 and 5 suggests that the desire to limit migration currently occurs not so much due to the hostile attitude towards migrants, but because of a lack of understanding of why do regional community need migrants under the conditions of a highly competitive labor market and the growth of social, financial and other costs with migration flows increase. This kind of "conservative tolerance" does not oppose migrants to the local 
population by ethno-national basis, but contains doubt whether liberal migration regime is useful in modern Russia.

Table 5. Distribution of answers to the question "Your attitude towards migrants and displaced people in your area..." (in \% of respondents)

\begin{tabular}{cc}
\hline Possible answers & Frequency, \% of respondents \\
\hline 1) I sympathize with them. & 36 \\
2) I am indifferent to them. & 29 \\
3) I dislike them. & 26 \\
4) Hard to say. & 10 \\
\hline
\end{tabular}

This tendency is evident in the respondents' answers to the question of the conditions under which migration is acceptable for them. Most of the respondents (46\%) indicate that migration, first of all, should not lead to deterioration of the living conditions of the local population. This fully applies not only to the situation in the labor market, but also to such aspect as "ethno-cultural security".

\section{Discussions}

Discussing the situation of conflict of interests and interethnic tensions we may conclude that "active use of ethnoresource" most often takes place in practice: various aspects of ethnicity, as solidarity, based on valid for a group task solutions of collective choice and action are included in a single complex. If the process of transformation of the economic zones include not factors of technological or productive efficiency, but such ethnoinstitutes as mutual support, group solidarity based on the division and delegation of responsibility, coercion based on the authority, ethnic systems of redistribution, if the economic displacement is accompanied by conscious or unconscious formation of an aggressive image of an etho-group that is functionally relevant to the situation of social competition, therefore the presence of ethnic components in an economic conflict can be debated.

Ethnoinstitutional interaction is well discovered in the context of diasporas processes. Rostov region has a long tradition of diaspora relations (Arutyunyan, 2010). They date back to the earliest days of the formation of Cossack communities as a key element that defines ethnic and social status of the region in the pre-revolutionary period (Turkic and Circassian component of the Cossacks) (Vodolatsky et al., 2011). The historical experience of Cossacks and Nakhichevan Armenians living side by side gives the concept of diaspora especially meaningful sense on Don. Thus, Rostov-on-Don by virtue of historical and cultural traditions of its development (the development of military and frontier village into a major industrial and commercial centre, territorial annexation and absorption of Nakhchivan as a separate city) has always been characterized by high level of tolerance towards representatives of different ethnic groups.

Historical experience of the largest ethnic groups neighborhood within the present Rostov region confirms the idea that the adaptation of diasporas as a social process involves a dual nature: the process of adaptation means not only the adaptation of diasporas to ethnic environment, but also a reaction of the majority. Certain social tension can also occur inside diasporas. It has interethnic competition nature. Armenian and Greek diasporas are traditional (it exist more than 200 years) and make up a large part of the Rostov region population and, in addition, demonstrate a degree of success in adaptation and integration in the regional community (Barkov et al., 2011). Significantly successful adaptation of the Greeks and Armenians is determined by such factors as:

a) The proximity of the value systems and mentality, based on Eastern Christianity of Greek and Slavic population;

b) The duration of cohabitation;

c) The active role of the Greeks and the diaspora as a whole in solving local territorial problems;

d) The diaspora renunciation of the independent political subjectivity.

\section{Summary}

At the moment it becomes apparent that restrained and cautious mood against migrants prevails in the Rostov region society. No social demand or approval on the migratory flows expansion occur. People become more conservative in this respect: they actually accept an ethno-cultural diversity, but they prefer it remains within a well-established ethnic balance and conforms such patterns of integration that are demonstrated by the oldest Rostov region diasporas: Armenians, Greeks, Koreans and others. In total more than $60 \%$ of respondents speak 
against not only expanding, but even preserving migration in the same amount. Only $15 \%$ of respondents agreed that the migrants need to be supported. Despite the fact that $36 \%$ indicate that their attitudes towards migrants would not change if after a communication with the migrants they realized that they knew Russian language, Russian culture well, the majority of respondents $(53 \%)$ emphasize the particular importance of the cultural complementarity and empathy. Therefore, this component should be considered as one of the basic principles of the state migration policy.

Based on the research findings, it might be argued that one of the basic principles of the state migration policy is providing an opportunity for migrants to get the knowledge of Russian culture and Russian language. Problems of learning and perception of Russian culture and Russian language by migrants will become the direction of research development in the future.

According to the results of our analysis we can formulate a number of recommendations to the Federal and regional authorities. First, understanding of the complex nature of migration should be a principal position in the formulation of migration policy. Migration cannot be regarded as simply a movement of people or the labour force. Many social structures (Diasporas, black niches of the economy, religious communities, etc) occur as consequences of migration flows and its development should be understandable.

In this regard, the question of information support of management decisions becomes actual. Besides collecting primary data on the number of migration and its direction it is necessary to develop comprehensive and statistical extrapolation models that predict the dynamics of quality of life depending on migration dynamics.

Thirdly, if the external labour migration can be limited rather quickly, then for reducing conflict risks of internal migration it is necessary to develop the institutions of mediation. There are several areas of work: a) strengthening the responsibility of the ethnic community for adaptation and integration of migrants in the new conditions; b) supporting civil society institutions (including religious communities) for their integration, educational work; c) translation of "transparent" norms of behavior and social living in the region; d) the improvement of preventive and operative work of law enforcement agencies in the areas of risk - social zones and economic niches, which have high potential for conflict due to competition between the newcomers and locals or other reasons.

\section{References}

Alexseev, A. M. (2006). Immigration phobia and the security dilemma: Russia, Europe, and the United States (pp. 8-12). N.Y.: Cambridge University Press.

Arutyunyan, Yu. V. (2010). Russian Armenians: the experience of socio-cultural adaptation. Obschestvennye nauki i sovremennost', 4, 92-99.

Barbashin, M. (2012). Institutes and ethnogenesis: Institutional reproduction of ethnic identity in local communities (pp. 99, 110). Rostov-on-Don.

Barkov, F. A., Mirzoyan, G. V., Serikov, A. V., \& others. (2011). Armenians in the South of Russia: the Experience of Sociological Research. Rostov-on-Don: Southern Russian Branch of Institute of Sociology of RAS.

Barkov, F. A., Serikov, A. V., \& Chernous, V. V. (2013). Competing of Civic and Ethnic Forms of Identity in Russia (Based on Regional Empirical Studies). World Applied Sciences Journal, 26(4).

Citizenship and Immigration Canada, 2014. Annual Report On The Operation Of The Canadian Multiculturalism Act (2012-2013). Retrieved May 15, 2014, from http://www.cic.gc.ca/english/pdf/pub/ multi-ann-report2013_e.pdf

Flynn, M. (2004). Migrant resettlement in the Russian Federation: Reconstructing homes and homelands (pp. 10-11). L.: Anthem Press.

Gorenburg, D. P. (2003). Minority Ethnic Mobilization in the Russian Federation (pp. 27-49). N.Y.: Cambridge University Press. http://dx.doi.org/10.1017/CBO9780511550348

Gudkov, L. D. (2012). "Trust” in Russia: the meaning, function, structure. The Russian Public Opinion Herald: Data. Analysis. Discussions, 2(112), 8-47.

Karanov, D. P. (2013). Migrants and the host society: The cultural dimension of interethnic relations in the urban environment. Politeia, 1(68), 24-35.

Kurabtsev, V. L. (2010). The Southern Federal District: The new wave of migration. Sotsiologicheskie Issledovaniya, 8, 77-90. 
Losifides, T. (2011). Qualitative Methods in Migration Studies: a Critical Realist Perspective (pp. 39-40). Farnham: Ashgate Publ. Ltd.

Morgunova, A. B. (2010). Migration. The problem? The Russian Public Opinion Herald: Data. Analysis. Discussions, 2(104), 89-100.

Police arrested a suspect in the murder of a student of the Rostov. In RIA "Novosti" web-site. Retrieved May 20, 2014, from http://ria.ru/inquest/20101212/307759310.html

Rozanova, M. S. (2010). Migration process, tolerance and migration policy in contemporary Russia. In N. Popson (Ed.), Demography, migration, and tolerance: Comparing the Russian, Ukrainian, and U.S. experience (pp. 36-37). Washington, D.C.: Woodrow Wilson International Center for Scholars.

Laruelle, M. (Ed.). (2009). Russian nationalism and the national reassertion of Russia (pp. 168-170). N.Y:: Taylor \& Francis e-Library.

Toschenko, Zh. T., \& Chaptykova, T. I. (1996). Diaspora as an object of sociological research. Sotsiologicheskie Issledovaniya, 12, 33-42.

Tsyganov, A. (2006). "They behaved defiantly ignoring the mentality of our people": The Head of Karelia has found the cause mass unrest. Retrieved May 5, 2014, from http://www.kommersant.ru/doc/702460

Vodolatsky, V. P., \& Volkov, Y. G. (2011). Cossacks as ethnosocial phenomenon of modern Russia (On the example of Don Cossacks). Rostov-on-Don: Southern Russian Branch of Institute of Sociology of RAS.

Zhou, M. (2013). Understanding Ethnicity from a Community Perspective. In S. J. Gold, \& S. J. Nawyn (Eds.), The Routledge International Handbook of Migration Studies (pp. 250-260). N.Y.: Routledge.

\section{Notes}

Note 1. Quick Caucasian folk dance and music to it.

Note 2. The research "Assessment of ethnic conflicts between migrants and the host population of Rostov region" was conducted in the summer, 2013 by RROO "Civil Concord" in conjunction with the faculty of Regional Studies of South Federal University and the Federal Migration Service in the Rostov region. Presentation of the results was held on 23.09.2013 in the South Federal University. Retrieved May 30, 2014, from http://www.fms-rostov.ru/ne_4979809/

\section{Copyrights}

Copyright for this article is retained by the author(s), with first publication rights granted to the journal.

This is an open-access article distributed under the terms and conditions of the Creative Commons Attribution license (http://creativecommons.org/licenses/by/3.0/). 